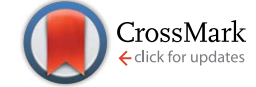

Cite this: RSC Adv., 2017, 7, 1336
Received 27th October 2016 Accepted 22nd November 2016

DOI: 10.1039/c6ra25894h

www.rsc.org/advances

\section{The extraction of essential oils from patchouli leaves (Pogostemon cablin Benth) using a microwave air-hydrodistillation method as a new green technique}

\begin{abstract}
Heri Septya Kusuma* and Mahfud Mahfud
Nowadays, patchouli oil extraction in Indonesia is generally carried out using conventional methods, although such methods require large amounts of energy, solvents in significant amounts, and quite a long time. Therefore, in this study, patchouli oil extraction was done using a microwave hydrodistillation method. In addition to optimizing the extraction process of patchouli oil, this study used a development of the microwave hydrodistillation method, microwave air-hydrodistillation. Based on this research, it can be seen that patchouli oil extraction using the microwave air-hydrodistillation method is faster, produces a better yield and a higher accumulation of recovery than extraction using the standard microwave hydrodistillation method. A gas chromatography-mass spectrometry analysis of the composition of the compounds in the patchouli oils shows that the heavy fraction components obtained by microwave air-hydrodistillation are more numerous than those obtained using the microwave hydrodistillation method. Furthermore, an analysis of the electric consumption and the environmental impact of the microwave air-hydrodistillation method for patchouli oil extraction indicates that this method can be considered a new green technique.
\end{abstract}

\section{Introduction}

Essential oils, also called ethereal oils or volatile oils, are natural plant extracts that come from leaves, flowers, wood, grain and even flower buds. There are at least 150 types of essential oils that have been traded in the international market and 40 types of them can be produced in Indonesia. ${ }^{1}$ Although many types of essential oils can be produced in Indonesia, only a small number of essential oils have been, or are being, commercially developed in Indonesia.

The industry of essential oil processing in Indonesia has existed since colonial times. However, the quality and quantity of production has not undergone many changes. This is due largely to the fact that volatile oil processing units still use simple or traditional technology and generally have limited production capacity. ${ }^{2}$

Indonesia is an agricultural country with tremendous natural resources and an abundance of various diverse types of plants. Indonesia, as one of the important essential oil exporting countries in the world, should pursue the development of the quality and value of its industries concerned with essential oils and their derivatives. The production of essential oils is

Department of Chemical Engineering, Institut Teknologi Sepuluh Nopember, Surabaya, Indonesia..E-mail: heriseptyakusuma@gmail.com; mahfud@chem-eng.its. ac.id; Tel: +6285730780240 a complex process. Increasing the efficiency of production requires increased crop productivity, improved post-harvest handling, better extraction methods and increased added value from control and quality assurance in order to obtain consistent high quality. ${ }^{2}$

In Indonesia there are 40 types of essential oils that are traded, 12 of which have long been grown and exported. Certain Indonesian essential oil products are dominant in the world market, such as patchouli oil (800 tons essential oil products), ylang ( 25 tons essential oil products), vetiver (30 tons essential oil products), citronella (500 tons essential oil products), nutmeg (350 tons essential oil products) and clove (2500 tons essential oil products). Regional export destinations include Europe, America, Australia, Africa, China, India, and ASEAN, ${ }^{1}$ among others.

The relatively good prospects for essential oils in Indonesia should be improved by the mastery of refining technology and the cultivation of essential oil producing plants, in order that the essential oil businesses are able to thrive in terms of the quality and quantity of their products, to meet the world's needs and to enhance their competitiveness relative to suppliers from other countries. This can be illustrated from the patchouli oil extraction process which is generally carried out by solvent extraction, ${ }^{3}$ hydrodistillation, ${ }^{4}$ steam-hydrodistillation ${ }^{5}$ and steam distillation. ${ }^{6}$

The extraction of patchouli oil carried out by patchouli farmer groups in Kuningan, West Java, Indonesia uses the 
steam distillation method, which has the capacity of $100 \mathrm{~kg}$ per kettle. The results of this extraction are from 2.2 to $2.8 \mathrm{~kg}$ for one patchouli oil extraction for eight hours. One extraction of patchouli oil by the steam distillation method can use kerosene 40 liters of kerosene. ${ }^{7}$

Therefore, new green techniques should be considered in the extraction of essential oils with the minimum use of energy, solvent, and time. New methods are being developed to extract essential oils, one of which uses the microwave (microwaveassisted extraction).

Previous research has shown that extraction with a microwave is an alternative that can be further developed, in contrast to the conventional method, because of its high levels of product purity, minimum use of solvent, and short processing time. ${ }^{8}$ One development is the microwave hydrodistillation method which is a combination of hydrodistillation by heating using a microwave ${ }^{9}$ and microwave steam distillation, in which the steam distillation is driven by heating using microwaves. ${ }^{10}$

In addition to optimizing the extraction process of essential oils, in this study we will use a development of the microwave hydrodistillation method, the microwave air-hydrodistillation method. The microwave air-hydrodistillation method is generally composed of three main parts: a compressor that serves to inject air into the distiller-containing matrix (the part of plants that contain essential oil) and solvent; a microwave which serves as the heater; and a condenser which serves as the cooling system. ${ }^{11}$

The addition of an air flow in the microwave airhydrodistillation method is expected to improve the yield and quality of the obtained patchouli oil. It is suspected that the additional air flow will play a role in helping to optimize the mixing process during extraction and the extraction of essential oil components which are inside the cell membrane or the plant tissue and do not diffuse out easily. This is because patchouli oil is a heavy oil which is suspected to contain several components in the heavy fraction which are difficult to extract without the addition of air flow. Thus to study the effect of the air flow on the microwave air-hydrodistillation method, in this research we will extract essential oils from the leaves of the patchouli (Pogostemon cablin Benth) by both microwave hydrodistillation and microwave air-hydrodistillation methods.

\section{Material and methods}

\section{Materials and chemicals}

The patchouli leaves (Pogostemon cablin Benth) used in this research were obtained from Trenggalek, East Java, Indonesia and stored at room temperature until required. The distilled water and anhydrous sodium sulphate used in the experimental work were of analytical grade.

\section{Microwave air-hydrodistillation method}

A domestic microwave oven (EMM-2007X, Electrolux, $20 \mathrm{~L}$, $800 \mathrm{~W}$; variable in $200 \mathrm{~W}$ increments, $2.45 \mathrm{GHz}$ ) was modified for the microwave hydrodistillation operation. The dimensions of the PTFE-coated cavity of the microwave oven were $46.1 \mathrm{~cm} \times$ $28.0 \mathrm{~cm} \times 37.3 \mathrm{~cm}$. Patchouli leaves $(40 \mathrm{~g})$ were placed in a $1 \mathrm{~L}$ flask containing deionized water $(400 \mathrm{~mL})$. The flask was set up within the microwave oven cavity and a condenser was used on the top (outside the oven) to collect the extracted essential oils. Using the compressor (MELZER V-777, electric motor: 1/5H.P., max pressure: $3 \mathrm{bar}$ ), air flow was added into the distiller containing the patchouli leaves and deionized water. The air flow was adjusted in accordance with the operational conditions and the determined research variables using a flow meter (Fig. 1). The microwave oven was operated at various power levels (264, 400 and $600 \mathrm{~W}$ ) for a period of $2 \mathrm{~h}$. This period was sufficient to extract all the essential oils from the sample. The essential oils were separated using a separating funnel. To remove water, the extracted essential oils were then dried over anhydrous sodium sulphate, weighed and stored in amber vials at $4{ }^{\circ} \mathrm{C}$ until they were used for analysis. The yield of patchouli oil was found by the following equation:

$$
y=\frac{V}{W} \times 100
$$

where $y$ is the patchouli oil yield $(\%, \mathrm{w} / \mathrm{w}), V$ is the weight or mass of extracted patchouli oil (g) and $W$ is the weight or mass of patchouli leaves $(\mathrm{g})$.

\section{Microwave hydrodistillation method}

Patchouli leaves $(40 \mathrm{~g})$ were placed in a $1 \mathrm{~L}$ flask containing deionized water $(400 \mathrm{~mL})$. The flask was setup within the microwave oven cavity and a condenser was used on the top (outside the oven) to collect the extracted essential oils (Fig. 2). The microwave oven was operated at various power levels (264, 400 and $600 \mathrm{~W}$ ) for a period of $2 \mathrm{~h}$. This period was sufficient to extract all the essential oils from the sample. The essential oils were separated using a separating funnel. To remove water, the extracted essential oils were then dried over anhydrous sodium sulphate, weighed and stored in amber vials at $4{ }^{\circ} \mathrm{C}$ until they were used for analysis.

\section{Kinetic modeling for the extraction processes}

In this study, kinetic modeling for the extraction of patchouli oil by the microwave hydrodistillation and microwave air-

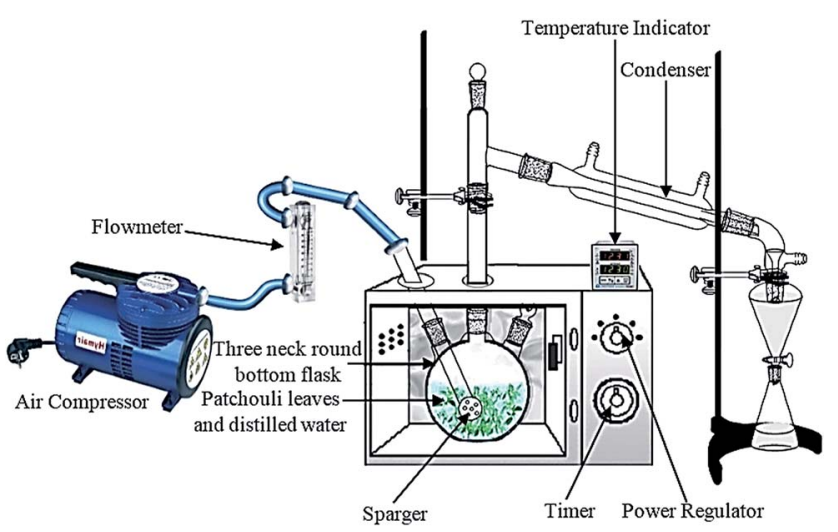

Fig. 1 The experimental setup for patchouli oil extraction by the microwave air-hydrodistillation method. 


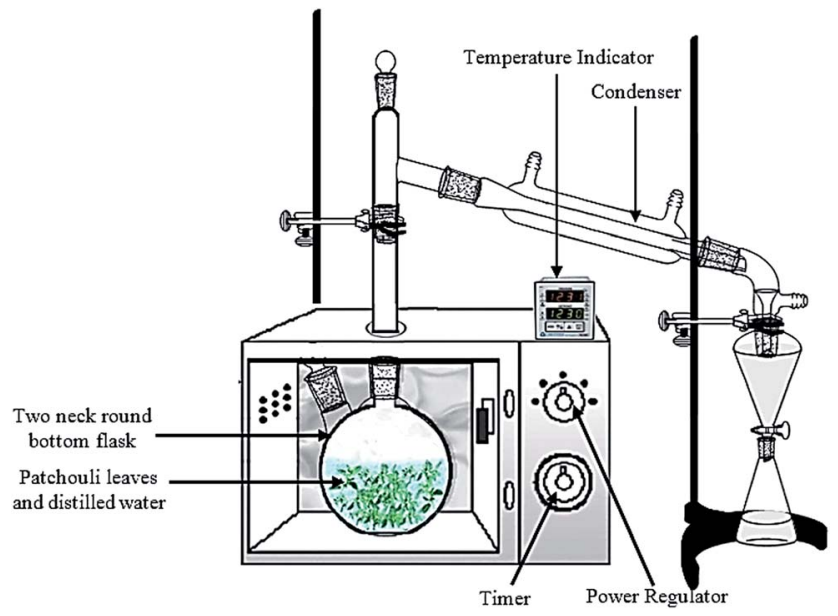

Fig. 2 The experimental setup for patchouli oil extraction by the microwave hydrodistillation method.

hydrodistillation methods was performed using the first-order and second-order models.

First-order kinetic model. The first-order kinetic equation by Lagergren $^{\mathbf{1 2 - 1 4}}$ can be written in differential form as follows:

$$
\frac{\mathrm{d} C_{t}}{\mathrm{~d} t}=k_{1}\left(C_{\mathrm{S}}-C_{t}\right)
$$

where $k_{1}\left(\mathrm{~min}^{-1}\right)$ is the first-order extraction rate constant and $t$ ( $\mathrm{min})$ is the extraction time.

Furthermore, eqn (3) can be obtained by integration with the boundary condition $C_{t}=0$ at $t=0$ and $C_{t}=C_{t}$ at $t=t$ :

$$
\ln \left(\frac{C_{\mathrm{S}}}{C_{\mathrm{S}}-C_{t}}\right)=k_{1} t
$$

Eqn (3) can be converted into a linear form as follows:

$$
\log \left(C_{\mathrm{S}}-C_{t}\right)=\log \left(C_{\mathrm{S}}\right)-\frac{k_{1}}{2.303} t
$$

Then a plot of $\log \left(C_{\mathrm{S}}-C_{t}\right)$ against $t$ gives a slope and intercept that can be used to determine the value of the firstorder extraction rate constant $\left(k_{1}\right)$ and the value of the extraction capacity $\left(C_{\mathrm{S}}\right)$, respectively.

Second-order kinetic model. The second-order kinetic equation for the rate of extraction can be written as follows: ${ }^{15}$

$$
\frac{\mathrm{d} C_{t}}{\mathrm{~d} t}=k_{2}\left(C_{\mathrm{S}}-C_{t}\right)^{2}
$$

where $k_{2}\left(\mathrm{~L} \mathrm{~g}^{-1} \mathrm{~min}^{-1}\right)$ is the second-order extraction rate constant.

By grouping variables, eqn (6) is obtained:

$$
\frac{\mathrm{d} C_{t}}{\left(C_{\mathrm{S}}-C_{t}\right)^{2}}=k_{2} \mathrm{~d} t
$$

Further, eqn (9) can be obtained by integrating eqn (6) using the boundary conditions $C_{t}=0$ at $t=0$ and $C_{t}=C_{t}$ at $t=t$ and by performing rearrangement as follows:

$$
\begin{gathered}
\frac{1}{\left(C_{\mathrm{S}}-C_{t}\right)}-\frac{1}{C_{\mathrm{S}}}=k_{2} t \\
C_{t}=C_{\mathrm{S}}-\frac{C_{\mathrm{S}}}{1+C_{\mathrm{S}} k_{2} t} \\
C_{t}=\frac{C_{\mathrm{S}}{ }^{2} k_{2} t}{1+C_{\mathrm{S}} k_{2} t}
\end{gathered}
$$

Eqn (9) is the integrated second-order extraction rate law and can be converted back into linear form as follows:

$$
\frac{t}{C_{t}}=\frac{1}{k_{2} C_{\mathrm{S}}^{2}}+\frac{t}{C_{\mathrm{S}}}
$$

The extraction rate $\left(C_{t} / t\right)$ can be obtained from eqn (11) as follows:

$$
\frac{C_{t}}{t}=\frac{1}{\left(1 / k_{2} C_{\mathrm{S}}{ }^{2}\right)+\left(t / C_{\mathrm{S}}\right)}
$$

and the initial extraction rate $(h)$, with $C_{t}=t$ when $t$ approaches 0 , can be defined as:

$$
h=k_{2} C_{\mathrm{S}}^{2}
$$

Eqn (9) can be changed again to give:

$$
\frac{t}{C_{t}}=\frac{t}{C_{\mathrm{S}}}+\frac{1}{h}
$$

The initial extraction rate $(h)$, the extraction capacity $\left(C_{\mathrm{S}}\right)$, and the second-order extraction rate constant $\left(k_{2}\right)$ can be determined experimentally from the slope and intercept of a plot between $t / C_{t}$ and $t$.

\section{Physical constants}

The specific gravity and refractive index of the essential oils extracted from patchouli leaves (by both extraction methods) were measured according to the method suggested by ISO 3757: $2002(\mathrm{E})$. The specific gravity and refractive index were measured at $20^{\circ} \mathrm{C}$.

\section{Chemical analysis of essential oil constituents}

The composition of the patchouli oils was determined by chemical analysis using gas chromatography coupled to mass spectrometry (GC-MS) on a Hewlett-Packard 6890 gas chromatograph coupled to a 5973A mass spectrometer, using two fused silica capillary columns with different stationary phases. The non-polar column was HP5MS ${ }^{\text {TM }}$ (30 m length, 0.25 diameter and $0.25 \mu \mathrm{m}$ film thickness) and the polar one was a Stabilwax $^{\mathrm{TM}}$ consisting of Carbowax ${ }^{\mathrm{TM}}$-PEG (60 m length, 0.25 $\mathrm{mm}$ diameter and $0.25 \mu \mathrm{m}$ film thickness). GC-MS spectra were obtained using the following conditions: carrier gas He; flow rate $1.0 \mathrm{~mL} \min ^{-1}$; split $1: 50$; injection volume $1.0 \mu \mathrm{L}$; injection temperature $300{ }^{\circ} \mathrm{C}$; oven temperature $100-250{ }^{\circ} \mathrm{C}$ at $10{ }^{\circ} \mathrm{C}$ $\min ^{-1}$; ionization voltage $70 \mathrm{eV}$; electron ionization mode. 
Identification was confirmed by comparison of the mass spectral fragmentation patterns with those stored in the MS database (National Institute of Standards and Technology and Wiley libraries) and with mass spectra literature data. ${ }^{\mathbf{1 6 , 1 7}}$ For each compound on the chromatogram, the percentage of peak area relative to the total peak areas from all compounds was determined such that the relative amount of each compound could be reported.

\section{Electric consumption}

The electric consumption of the different extraction methods was calculated based on the influence of power consumption and extraction time. The general equation for electric consumption is described by eqn (14):

$$
E_{\mathrm{C}}=\frac{P t}{3600000}
$$

where $E_{\mathrm{C}}$ is electric consumption ( $\mathrm{kW} \mathrm{h}$ ), $P$ is power consumption (W) and $t$ is time (s).

Additionally, the relative electric consumption of the different extraction methods could be expressed by eqn (15):

$$
E_{\mathrm{C}}^{*}=\frac{E_{\mathrm{C}}}{m}
$$

where $E_{\mathrm{C}}^{*}$ is relative electric consumption $\left(\mathrm{kW} \mathrm{h} \mathrm{g}^{-1}\right)$ and $m$ is the mass of obtained essential oil $(\mathrm{g})$.

\section{$\mathrm{CO}_{2}$ emission}

The measurements of $\mathrm{CO}_{2}$ emitted were carried out based on the procedures mentioned in previous studies: to obtain $1 \mathrm{~kW} \mathrm{~h}$ of energy from coal or fossil fuels, $800 \mathrm{~g}$ of $\mathrm{CO}_{2}$ will be released into the atmosphere during combustion. ${ }^{8}$ Thus $\mathrm{CO}_{2}$ emission is described by eqn (16):

$$
E_{\mathrm{CO}_{2}}=\frac{E_{\mathrm{C}} 800}{1000}
$$

where $E_{\mathrm{CO}_{2}}$ is $\mathrm{CO}_{2}$ emission $(\mathrm{kg})$ and $E_{\mathrm{C}}$ is electric consumption (kW h).

The relative $\mathrm{CO}_{2}$ emission of the different extraction methods was calculated according to eqn (17):

$$
E_{\mathrm{CO}_{2}}^{*}=\frac{E_{\mathrm{CO}_{2}}}{m}
$$

where $E_{\mathrm{CO}_{2}}^{*}$ is the relative $\mathrm{CO}_{2}$ emission $\left(\mathrm{kg} \mathrm{g}^{-1}\right)$ and $m$ is the mass of obtained essential oil (g).

\section{Results and discussion}

The effect on patchouli yield of the addition of air flow in the microwave air-hydrodistillation method

In this study both microwave hydrodistillation and microwave air-hydrodistillation methods were used to compare the yield and quality of the obtained patchouli oil and to study the effect of air flow on the microwave air-hydrodistillation method. In order to be able to compare the yields of patchouli oil obtained by microwave hydrodistillation and microwave airhydrodistillation, data on patchouli oil extraction at various microwave power settings were collected with a defined ratio of raw material to solvent.

In general it can be seen that the yield of patchouli oil obtained by the microwave air-hydrodistillation method was higher when compared with that obtained by the microwave hydrodistillation method. The comparison chart of patchouli oil yield obtained by the microwave hydrodistillation and microwave airhydrodistillation methods at various microwave power levels can be seen in Fig. 3. Based on Fig. 3 it can be seen that with increasing air flow rate, the yield of patchouli oil increased. In addition, from Fig. 3 it can be seen that the increase of patchouli oil yield was most significant when extraction was done by microwave air-hydrodistillation using air flow rates of 0 to $3.0 \mathrm{~L}$ $\min ^{-1}$. Meanwhile, if the air flow rate used in the microwave airhydrodistillation method was increased to $5.0 \mathrm{~L} \mathrm{~min}^{-1}$, the obtained patchouli oil yield was relatively constant or almost equal to the patchouli oil yield obtained by microwave airhydrodistillation using an air flow rate of $3.0 \mathrm{~L} \mathrm{~min} \mathrm{~m}^{-1}$.

To further determine the effect of air flow on the microwave air-hydrodistillation method for the extraction of patchouli oil, the extraction was conducted using a microwave power of $600 \mathrm{~W}$ at the ratio of patchouli leaves to distilled water of $0.10 \mathrm{~g} \mathrm{~mL}^{-1}$. The extraction using the microwave hydrodistillation method produced a patchouli oil yield of $1.9437 \pm 0.0888 \%$ while extraction using microwave air-hydrodistillation with an air flow rate of $5.0 \mathrm{~L} \mathrm{~min}^{-1}$ produced a patchouli oil yield of 2.7678 $\pm 0.1993 \%$. The microwave hydrodistillation method took up to 40 minutes to obtain a yield of $1.5167 \pm 0.1184 \%$, while the microwave air-hydrodistillation method only took 20 minutes to obtain almost the same yield $(1.5758 \pm 0.2004 \%)$. In addition, the microwave hydrodistillation method took up to 120 minutes to obtain a yield of $1.9437 \pm 0.0888 \%$, while the microwave airhydrodistillation method took only 30 minutes to obtain almost the same yield $(1.9204 \pm 0.1981 \%)$. A comparison chart of the patchouli oil yields obtained using microwave hydrodistillation and microwave air-hydrodistillation (air flow rate $5.0 \mathrm{~L} \mathrm{~min}^{-1}$ ) can be seen in Fig. 4.

The microwave air-hydrodistillation method could produce higher yields of patchouli oil when compared with the microwave hydrodistillation method, because the air flow helps to

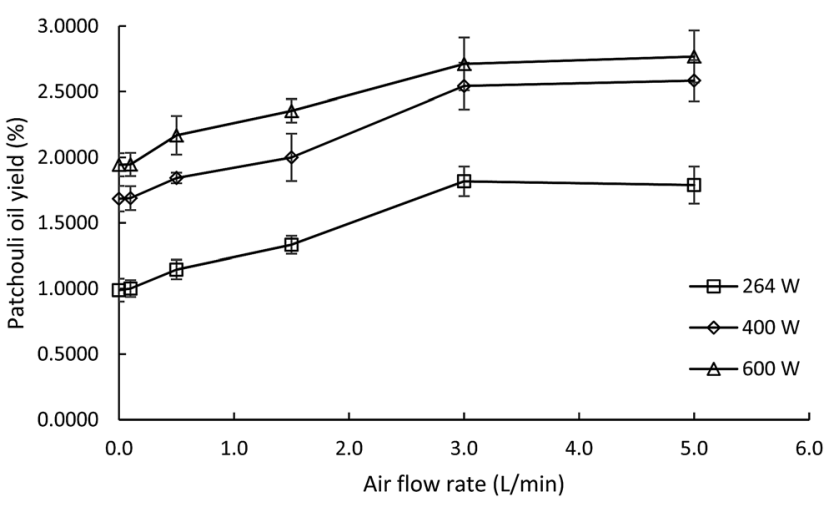

Fig. 3 The effect of the air flow rate on the yield of patchouli oil extracted at different microwave power levels. The ratio of patchouli leaves to distilled water was $0.10 \mathrm{~g} \mathrm{~mL}^{-1}$. 
optimize the mixing process at the time of extraction; this stirring process directly affects the mass transfer process in the solvent phase. This then causes the equilibrium between the liquid and vapor phases to be achieved more quickly when using microwave air-hydrodistillation to extract the patchouli oil than when using microwave hydrodistillation. ${ }^{\mathbf{1 1}}$

In addition, the air flow may be involved in helping to extract essential oil components that are inside the cell membrane or the plant tissue and do not diffuse out easily. This is because patchouli oil is one of the heavy oils, containing several components in the heavy fraction that are difficult to extract without any air flow. To identify and confirm the components of the heavy fraction that are difficult to extract without air flow, the composition of the compounds in patchouli oil obtained by the microwave hydrodistillation and microwave airhydrodistillation methods are shown in Table 5. In general, it can be seen that the patchouli oil obtained by the microwave air-hydrodistillation method contains higher numbers and quantities of components than are obtained using the microwave hydrodistillation method. Thus the presence of an air flow in the microwave air-hydrodistillation method can also be said to facilitate the evaporation and transfer of the essential oil components contained in the material, improving the yield of patchouli oil obtained.

\section{Comparison of recovery in patchouli oil extraction by the microwave hydrodistillation and microwave air- hydrodistillation methods}

In this study, we conducted recovery calculations to determine how much influence the use of the air flow in the microwave airhydrodistillation method had in extracting the essential oils contained in the leaves. The accumulated value of recovery can be obtained by comparing the patchouli oil yield obtained from each method with the patchouli oil yield obtained from the Soxhlet method (2.7709\%).

Patchouli oil extraction using the microwave hydrodistillation and microwave air-hydrodistillation methods produced different accumulated recovery results. The

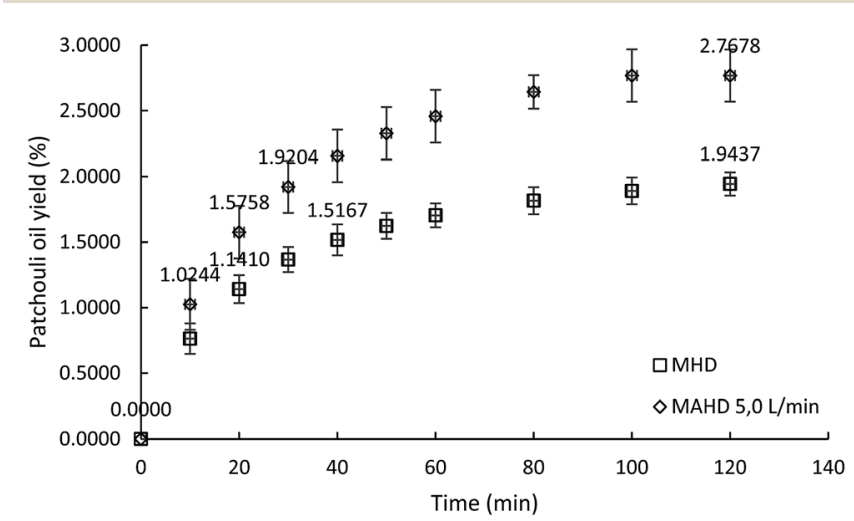

Fig. 4 Comparison between the yields of patchouli oil obtained by microwave hydrodistillation and microwave air-hydrodistillation (air flow rate $5.0 \mathrm{~L} \mathrm{~min}^{-1}$ ). The microwave power was $600 \mathrm{~W}$ and the ratio of patchouli leaves to distilled water was $0.10 \mathrm{~g} \mathrm{~mL}^{-1}$. accumulated recovery values for the extraction of patchouli oil using the microwave hydrodistillation and microwave airhydrodistillation methods can be seen in Fig. 5. It can be seen that the highest accumulated recovery value for patchouli oil extraction using microwave hydrodistillation was $70.1456 \%$, obtained when the patchouli oil extraction was done using a microwave power of $600 \mathrm{~W}$ and a ratio of patchouli leaves to distilled water of $0.10 \mathrm{~g} \mathrm{~mL}^{-1}$. The highest accumulated recovery value for the microwave air-hydrodistillation method was $99.8863 \%$, obtained when the patchouli oil extraction was done using a microwave power of $600 \mathrm{~W}$, a ratio of patchouli leaves to distilled water of $0.10 \mathrm{~g} \mathrm{~mL}^{-1}$ and an air flow rate of $5.0 \mathrm{~L} \mathrm{~min}^{-1}$.

The patchouli oil extraction using microwave hydrodistillation can be said to be less effective because it takes a longer time to produce the same recovery accumulation when compared with the microwave air-hydrodistillation method. From Fig. 5 it can be seen that the longer the extraction time, the greater the accumulated recovery of patchouli oil. For patchouli oil extraction using the microwave hydrodistillation and microwave air-hydrodistillation methods, the fastest increase occurred in the extraction time 0-40 min. After $40 \mathrm{~min}$, the increase in the accumulated recovery of patchouli oil became less significant.

The recovery of patchouli oil extracted using the microwave hydrodistillation and microwave air-hydrodistillation methods showed a decrease during the extraction process (Fig. 6). The decrease of patchouli oil recovery over the long extraction time may be due to the fact that diffusion between the steam and essential oils from inside the material (patchouli leaves) becomes increasingly slow as the essential oil content in the materials (patchouli leaves) decreases.

In addition, the decrease of patchouli oil recovery is very significant at the beginning of the extraction process which could be caused by the fact that many of the components of patchouli oil are polar (have high dipolar moments) and are extracted at the beginning of the extraction process. This is because the efficiency of extraction using microwave heating (microwave-assisted extraction) is higher if the target

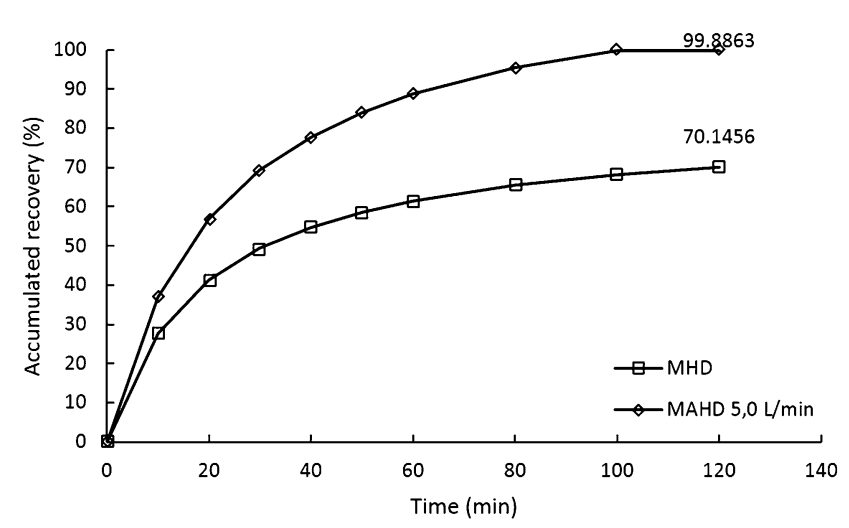

Fig. 5 Accumulated recovery of patchouli oil obtained by microwave hydrodistillation (MHD) and microwave air-hydrodistillation (MAHD; air flow rate $5.0 \mathrm{~L} \mathrm{~min}^{-1}$ ). The microwave power was $600 \mathrm{~W}$ and the ratio of patchouli leaves to distilled water was $0.10 \mathrm{~g} \mathrm{~mL}^{-1}$. 


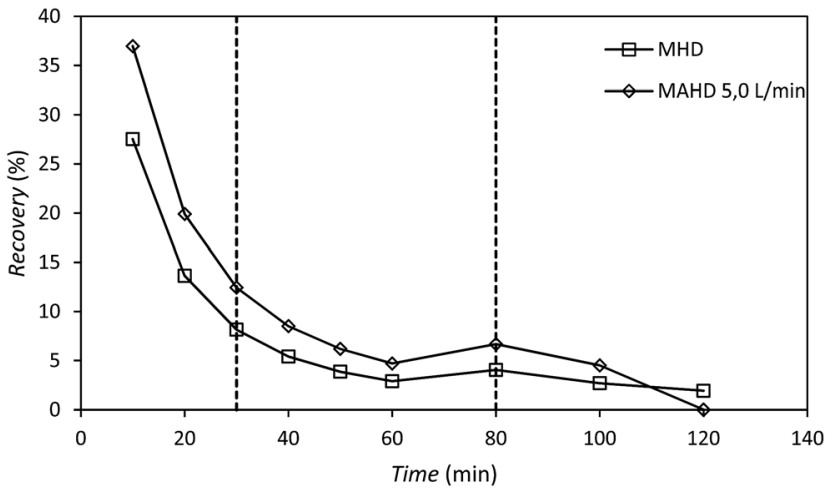

Fig. 6 Recovery of patchouli oil obtained by microwave hydrodistillation (MHD) and microwave air-hydrodistillation (MAHD; air flow rate $5.0 \mathrm{~L} \mathrm{~min}^{-1}$ ). The microwave power was $600 \mathrm{~W}$ and the ratio of patchouli leaves to distilled water was $0.10 \mathrm{~g} \mathrm{~mL}^{-1}$.

compound to be extracted and/or the solvents are polar. ${ }^{11}$ Organic compounds contained in the essential oil may have either high or low dipolar moments. The organic compounds contained in the essential oil that have high dipolar moments will interact better with the microwaves and will be extracted more easily than the aromatic compounds which have low dipolar moments.

The decrease of patchouli oil recovery is shown by the slope of the graph. Generally the slope of the line can be divided into three phases: phase I, 0-30 min; phase II, 30-80 min; and phase III, 80-120 min; where the longer the extraction time, the lower the recovery rate of patchouli oil (Table 1). Based on the accumulated recovery values for patchouli oil, it can be said that the addition of air flow in the microwave air-hydrodistillation method causes the extraction (recovery) of more patchouli oil from the material (patchouli leaves) when compared with the microwave hydrodistillation method.

\section{Kinetic modeling of patchouli oil extraction with microwave hydrodistillation and microwave air-hydrodistillation methods}

In the patchouli oil extraction using the microwave hydrodistillation and microwave air-hydrodistillation methods, it can be seen that the yield of the obtained patchouli oil increases rapidly at the beginning and then declines as the length of the

Table 1 Recovery of patchouli oil obtained by microwave hydrodistillation and microwave air-hydrodistillation (air flow rate $5.0 \mathrm{~L}$ $\mathrm{min}^{-1}$ ). The microwave power was $600 \mathrm{~W}$ and the ratio of patchouli leaves to distilled water was $0.10 \mathrm{~g} \mathrm{~mL}^{-1}$

\begin{tabular}{llll}
\hline & \multicolumn{3}{l}{ Recovery of essential oil (\%) } \\
\cline { 2 - 4 } & $\begin{array}{l}\text { Phase I, } \\
\text { Extraction method }\end{array}$ & Phase II, & Phase III, \\
\hline Microwave hydrodistillation & 49.3233 & 16.2096 & 4.6127 \\
$\begin{array}{l}\text { Microwave air-hydrodistillation } \\
\text { (5.0 L min }\end{array}$ & 69.3053 & 26.0732 & 4.5100
\end{tabular}

extraction time increases. The changes in the yield of the obtained patchouli oil can be demonstrated from a plot of the yield against the extraction time. This can be used to determine and study the kinetic model for patchouli oil extraction using the microwave hydrodistillation and microwave airhydrodistillation methods.

The first-order kinetic model for patchouli oil extraction using the microwave hydrodistillation and microwave airhydrodistillation (air flow rate $5.0 \mathrm{~L} \mathrm{~min}^{-1}$ ) methods can be studied from plots of $\log \left(C_{\mathrm{S}}-C_{t}\right)$ against $t$. Furthermore the linearization of each plot means that the slope and intercept can later be used to determine the values of $k_{1}, C_{\mathrm{S}}$ and the coefficient of determination $\left(R^{2}\right)$. In addition, the values of $k_{1}$ and $C_{\mathrm{S}}$ can be determined by minimization of the sum of the squared errors between the experimental data and the model data (data obtained from the mathematical model of the firstorder kinetic model) using Solver (Table 2). Generally from Table 2 it can be seen that the first order kinetic model for patchouli oil extraction using microwave hydrodistillation and microwave air-hydrodistillation (air flow rate $5.0 \mathrm{~L} \mathrm{~min}^{-1}$ ) has a coefficient of determination $\left(R^{2}\right)$ which is relatively low. Therefore the first order kinetic model does not represent well the experimental results of patchouli oil extraction using the microwave hydrodistillation and microwave airhydrodistillation methods. This conclusion is supported by Ho and McKay $(1999)^{18}$ which states that not all processes can be explained well by the first order kinetic model. In addition Covelo et al. (2004) ${ }^{19}$ states that the first order kinetic model can only represent well those processes that have just one mechanism.

Although the first-order kinetic model is less able to represent the experimental results of patchouli oil extraction using the microwave hydrodistillation and microwave airhydrodistillation methods, it can be used to represent the experimental results of extraction using the conventional method (hydrodistillation). To study this, we also conducted patchouli oil extraction using the conventional method (hydrodistillation) (Fig. 7).

Based on Table 2 it can be seen that the first order kinetic model for the extraction of patchouli oil using the conventional method (hydrodistillation) has a relatively high coefficient of determination, $R^{2}=0.9976$. Therefore, it can be said that the first order kinetic model could represent well the experimental results of patchouli oil extraction using the conventional method (hydrodistillation). This can be explained because in the patchouli oil extraction using the conventional method (hydrodistillation), there is only one mechanism that is important, namely the ability of the components of patchouli oil to dissolve in distilled water. This accords with Covelo et al. $(2004)^{19}$ which states that the first order kinetic model can only represent well those processes that have just one mechanism.

In the patchouli oil extraction using the microwave hydrodistillation and microwave air-hydrodistillation methods, in general there are two mechanisms. The first mechanism is the changing of the cells' matrix structure caused by electromagnetic waves. In this stage, the microwaves interact with water molecules contained within the glands and the vascular 
Table 2 Linearization of the first order kinetic model for patchouli oil extraction using microwave hydrodistillation, microwave air-hydrodistillation (air flow rate $5.0 \mathrm{~L} \mathrm{~min}^{-1}$ ) and conventional (hydrodistillation) methods. The microwave power was $600 \mathrm{~W}$ and the ratio of patchouli leaves to distilled water was $0.10 \mathrm{~g} \mathrm{~mL}^{-1}$

\begin{tabular}{|c|c|c|c|c|c|c|}
\hline Extraction methods & Calculation method & Slope $\mathrm{e}^{a}$ & $k_{1}, \min ^{-1}$ & Intercept $^{a}$ & $C_{\mathrm{S}}, \mathrm{g} \mathrm{L}^{-1}$ & $R^{2 a}$ \\
\hline Microwave hydro-distillation & $\begin{array}{l}\text { Linear regression } \\
\text { Solver }^{a}\end{array}$ & -0.0039 & $\begin{array}{l}0.0090 \\
0.0090\end{array}$ & 0.3135 & $\begin{array}{l}2.0583 \\
2.0583\end{array}$ & 0.8556 \\
\hline $\begin{array}{l}\text { Microwave air-hydro-distillation } \\
\left(5.0 \mathrm{~L} \mathrm{~min}^{-1}\right)\end{array}$ & $\begin{array}{l}\text { Linear regression } \\
\text { Solver }^{a}\end{array}$ & -0.0257 & $\begin{array}{l}0.0592 \\
0.0591\end{array}$ & 0.6815 & $\begin{array}{l}4.8029 \\
4.8024\end{array}$ & 0.9076 \\
\hline Hydrodistillation & $\begin{array}{l}\text { Linear regression } \\
\text { Solver }^{a}\end{array}$ & -0.0014 & $\begin{array}{l}0.0032 \\
0.0032\end{array}$ & 0.4252 & $\begin{array}{l}2.6620 \\
2.6620\end{array}$ & 0.9976 \\
\hline
\end{tabular}

system of the matrix. Thus the system undergoes a dramatic expansion, which is followed by the rupture of the network. The rupture of this network then allows the components of the essential oils to come out. The second mechanism is the strong absorption of microwave energy by the organic compounds contained in the essential oils. The organic compounds which have either high or low dipolar moments can be extracted with specific compositions. However, the organic compounds found in the essential oil that have high dipolar moments will interact better with the microwaves and can be extracted more easily when compared with the aromatic compounds which have low dipolar moments. ${ }^{11}$ In addition, Table 3 and Fig. 8 show that the second-order kinetic model
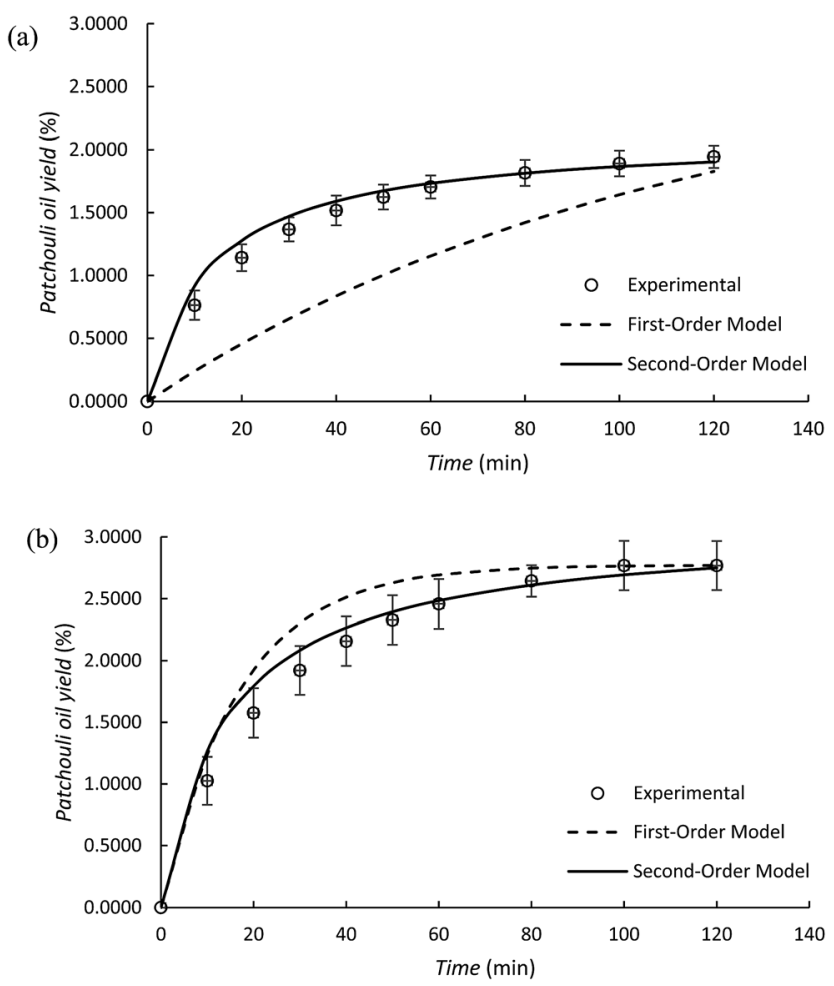

Fig. 7 A comparison of the first-order and second-order kinetic models with the experimental results for the extraction of patchouli oil by (a) microwave hydrodistillation and (b) microwave air-hydrodistillation (air flow rate $5.0 \mathrm{~L} \mathrm{~min}^{-1}$ ). The microwave power was $600 \mathrm{~W}$ and the ratio of patchouli leaves to distilled water was $0.10 \mathrm{~g} \mathrm{~mL}^{-1}$. can also be used to represent well the experimental results of patchouli oil extraction using the conventional method (hydrodistillation). It can be seen that the coefficient of determination $\left(R^{2}\right)$ is relatively high $\left(R^{2}=0.9960\right)$ and similar to that obtained with the first order kinetic model.

The values of the first-order extraction rate constants $\left(k_{1}\right)$ and the extraction capacities $\left(C_{\mathrm{S}}\right)$ obtained from the first-order kinetic model are higher for the extraction of patchouli oil using the microwave hydrodistillation and microwave airhydrodistillation methods than for extraction using the conventional method (hydrodistillation). This is the reason why patchouli oil extraction using microwave hydrodistillation and microwave air-hydrodistillation is quicker when compared with the extraction using the conventional method (hydrodistillation). It also can be seen that the values for the first-order extraction rate constant $\left(k_{1}\right)$ and extraction capacity $\left(C_{\mathrm{S}}\right)$ for patchouli oil extraction using the microwave airhydrodistillation method are higher than those obtained with microwave hydrodistillation. Thus the addition of air flow in the microwave air-hydrodistillation method can make the extraction process for patchouli oil run faster when compared with the use of microwave hydrodistillation alone.

It has been explained previously that in patchouli oil extraction using the microwave hydrodistillation or microwave air-hydrodistillation methods, in general there are two mechanisms, so this research also studied the use of the second-order kinetic model to represent the experimental results from these extraction processes. This can be done by making plots of $t / C_{t}$ against $t$. The linearization of each plot provides a slope and intercept that can later be used to determine the values of $k_{2}, C_{\mathrm{S}}$ and the coefficient of determination $\left(R^{2}\right)$. In addition, the determination of values of $k_{2}$ and $C_{\mathrm{S}}$ can be done by minimization of the sum of the squared errors between the experimental data and the model data (data obtained from the mathematical model of the second-order kinetic model) using Solver (Table 3). Generally, from Table 3, it can be seen that the second-order kinetic model for patchouli oil extraction using the microwave hydrodistillation and microwave airhydrodistillation (air flow rate $5.0 \mathrm{~L} \mathrm{~min}^{-1}$ ) methods has relatively high coefficient of determination $\left(R^{2}\right)$ values. Therefore it can be said that the second-order kinetic model can represent well the experimental results of patchouli oil extraction using the microwave hydrodistillation and microwave airhydrodistillation methods. 
Table 3 Linearization of the second order kinetic model for patchouli oil extraction using microwave hydrodistillation, microwave air-hydrodistillation (air flow rate $5.0 \mathrm{~L} \mathrm{~min}^{-1}$ ) and conventional (hydrodistillation) methods. The microwave power was $600 \mathrm{~W}$ and the ratio of patchouli leaves to distilled water was $0.10 \mathrm{~g} \mathrm{~mL}^{-1}$

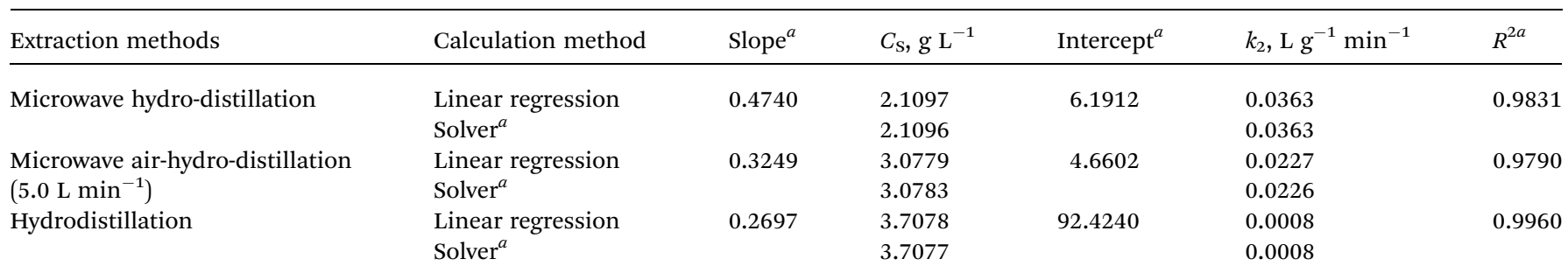

${ }^{a}$ Values obtained from Microsoft Excel®.

Based on the values of the second-order rate constant for extraction $\left(k_{2}\right)$ which have been obtained from the second-order kinetic model, it can be said that the rate constants for the extraction of patchouli oil using microwave hydrodistillation and microwave air-hydrodistillation are much higher (ca. 28.25 times and 43.375 times, respectively) than that obtained for extraction using the conventional method (hydrodistillation). However, from the second-order kinetic model, it can be said that the value of extraction capacity $\left(C_{\mathrm{S}}\right)$ for patchouli oil extraction using the conventional method (hydrodistillation) is higher (about 1.20451.7575 times) when compared with the extraction capacities obtained using the microwave hydrodistillation and microwave airhydrodistillation methods. Although the extraction of patchouli oil using the microwave hydrodistillation and microwave airhydrodistillation methods has lower values of extraction capacity $\left(C_{\mathrm{S}}\right)$ than obtained from extraction using the conventional method (hydrodistillation), the much higher values of the second-order extraction rate constants using the microwave hydrodistillation and microwave air-hydrodistillation methods explain why the extraction of patchouli oil using the microwave hydrodistillation and microwave air-hydrodistillation methods is faster when compared with the extraction using the conventional method (hydrodistillation).

Also based on the values of the second-order extraction rate constants $\left(k_{2}\right)$ obtained from the second-order kinetic model

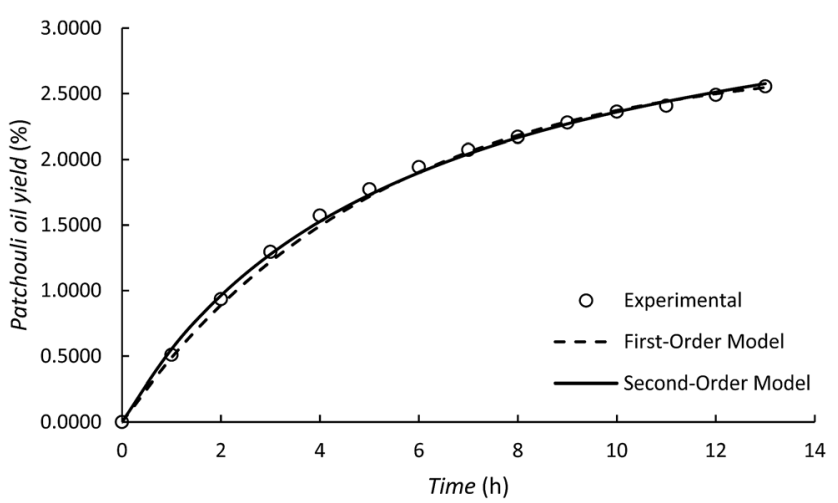

Fig. 8 A comparison of the first-order and second-order kinetic models with the experimental results for the extraction of patchouli oil by the conventional method (hydrodistillation). The ratio of patchouli leaves to distilled water was $0.10 \mathrm{~g} \mathrm{~mL}^{-1}$.
(Table 3), it can be said that the second-order extraction rate constant obtained using the microwave hydrodistillation method is higher (about 1.6062 times) than that obtained using microwave air-hydrodistillation. In contrast, the value of extraction capacity $\left(C_{\mathrm{S}}\right)$ obtained from the second-order kinetic model using the microwave air-hydrodistillation method is higher (about 1.4592 times) than that obtained with extraction using microwave hydrodistillation.

Although the extraction of patchouli oil using microwave airhydrodistillation has a lower second-order extraction rate constant than the extraction using the microwave hydrodistillation method, the value of extraction capacity $\left(C_{\mathrm{S}}\right)$ using microwave air-hydrodistillation is higher which explains why the extraction of patchouli oil using the microwave airhydrodistillation method is faster when compared with the extraction using microwave hydrodistillation. This is also supported by the equation for the extraction rate $\left(C_{t} / t\right)$ (eqn (11)) as follows:

$$
\frac{C_{t}}{t}=\frac{1}{\left(1 / k_{2} C_{\mathrm{S}}^{2}\right)+\left(t / C_{\mathrm{S}}\right)}
$$

The equation shows that the extraction capacity $\left(C_{\mathrm{s}}\right)$ has more effect than the value of the second-order extraction rate constant $\left(k_{2}\right)$. Thus the second-order kinetic model can also be used to explain why the addition of the air flow in the microwave air-hydrodistillation method can make the extraction process run faster when compared with the method using microwave hydrodistillation.

\section{Analysis of the physical and chemical properties of patchouli oil obtained by the microwave hydrodistillation and microwave air-hydrodistillation methods}

In determining the quality of patchouli oil obtained by microwave hydrodistillation and microwave air-hydrodistillation, it is necessary to test the physical and chemical properties of the essential oils obtained. This can be done by determining the densities and refractive indexes of the oils and identifying the composition of the compounds contained in the essential oils using GC-MS. In addition, a comparison of the physical and chemical properties of the extracts with quality standards data can be used to obtain an overview of the purity and quality of the essential oils and determine the presence or absence of 
Table 4 Analysis of the physical properties of patchouli oil obtained by microwave hydrodistillation and microwave air-hydrodistillation (air flow rate $5.0 \mathrm{~L} \mathrm{~min}-1$ ). The microwave power was $600 \mathrm{~W}$ and the ratio of patchouli leaves to distilled water was $0.10 \mathrm{~g} \mathrm{~mL}^{-1}$

\begin{tabular}{|c|c|c|c|c|}
\hline Extraction methods & Refractive index & Density & Refractive index & Density \\
\hline $\begin{array}{l}\text { Microwave air-hydro- } \\
\text { distillation }\left(5.0 \mathrm{~L} \mathrm{~min}^{-1}\right)\end{array}$ & $1.5050-1.5150\left(20^{\circ} \mathrm{C}\right)$ & $0.9520-0.9750\left(20^{\circ} \mathrm{C} / 20^{\circ} \mathrm{C}\right)$ & $1.5057-1.5157\left(20^{\circ} \mathrm{C}\right)$ & $0.9536-0.9755\left(20^{\circ} \mathrm{C} / 20^{\circ} \mathrm{C}\right)$ \\
\hline
\end{tabular}

components of the essential oil. However, the physical and chemical properties are not necessarily related directly to the aroma produced by the essential oil. ${ }^{20}$

Based on the analysis of the physical properties of the patchouli oil obtained by the microwave hydrodistillation and microwave air-hydrodistillation methods, it can be said that the values for the refractive indexes and densities of the obtained patchouli oils are in accordance with quality standards. It can also be seen that the values for the refractive indexes and densities of the patchouli oil do not show any significant differences for the two extraction methods. Thus it can be predicted that the patchouli oil obtained by microwave airhydrodistillation has a quality (refractive index and density) that is equal to that of patchouli oil obtained using the microwave hydrodistillation method. The results of the analysis of the physical properties of patchouli oil obtained by the microwave hydrodistillation and microwave air-hydrodistillation methods can be seen in Table 4 .

The analysis of the chemical properties of patchouli oil obtained by the microwave hydrodistillation and microwave airhydrodistillation methods indicates the quality of the obtained patchouli oil from some of the main compounds such as: patchouli alcohol, $\delta$-guaiene, $\alpha$-guaiene, $\alpha$-patchoulene and $\beta$ caryophyllene. The composition of the patchouli oil-based quality standard ISO 3757: 2002(E) is as follows: patchouli alcohol $27-35 \%$; $\delta$-guaiene $13-21 \%$; $\alpha$-guaiene $11-16 \%$; $\beta$-caryophyllene $2-5 \%$; and copaene $0-1 \%$. Generally the patchouli oil composition obtained by the microwave hydrodistillation and microwave air-hydrodistillation methods can be said to be in accordance with this quality standard. However there are some components that do not meet the quality standard ISO 3757: 2002 (E). For example, the content of patchouli alcohol in the patchouli oils obtained by microwave hydrodistillation (26.32\%) and microwave air-hydrodistillation $(25.23 \%)$ do not meet the quality standard ISO 3757: 2002(E) which specifies a minimum content of patchouli alcohol of $27 \%$. Moreover, it can be seen that the content of $\beta$-caryophyllene in the patchouli oil obtained by microwave air-hydrodistillation (5.42\%) does not meet the quality standard ISO 3757: 2002 (E) which specifies a maximum content of $\beta$-caryophyllene of $5 \%$.

An analysis done by Betts (1994) ${ }^{21}$ also showed that commercial samples of patchouli oil (Rivendell, Bunbury, Western Australia) contain the main compounds patchouli alcohol, $\delta$ guaiene, $\alpha$-guaiene, $\alpha$-patchoulene and $\beta$-caryophyllene with the composition: patchouli alcohol $28.5 \%$; $\delta$-guaiene $12.0 \%$; $\alpha$ guaiene $10.4 \%$; $\alpha$-patchoulene $6.4 \%$; and $\beta$-caryophyllene $4.7 \%$. Therefore it can be said that the patchouli oils obtained by microwave hydrodistillation and microwave air-hydrodistillation have qualities that are similar to those of commercial patchouli oil. The composition of the compounds contained in the patchouli oils obtained by microwave hydrodistillation and microwave air-hydrodistillation can be seen in Table 5 .

Table 5 shows that in general the number of compounds in the patchouli oil obtained by the microwave air-hydrodistillation method is greater when compared with the oil obtained by microwave hydrodistillation. In the patchouli oil extraction using microwave hydrodistillation, 21 compounds were detected while in the patchouli oil extraction using microwave airhydrodistillation, 26 compounds were detected. Thus, based on the analysis of the compound compositions of the extracted patchouli oils, it can be said that the addition of the air flow in the microwave air-hydrodistillation method can help to extract the heavy fraction components that are inside the cell membrane or the plant tissue and do not diffuse out easily. A greater number of heavy fraction components are contained in the patchouli oil obtained by the microwave air-hydrodistillation method than in the oil obtained by the microwave hydrodistillation method. In the extraction of patchouli oil by microwave hydrodistillation, there are only three heavy fraction components (mol. weight $\geq 228.41$ ) while in the extraction of patchouli oil by microwave air-hydrodistillation there are seven heavy fraction components (mol. weight $\geq 228.41$ ).

The heavy fraction components of patchouli oil are important oil components. This is because most of the components of the heavy fraction are oxygenated terpenes which can be said to be the most important component group in the essential oil because the oxygenated terpenes contribute more to the aroma produced by the essential oil than other group components. ${ }^{22}$ Therefore, the increased number of oxygenated terpene components contained in the patchouli oil obtained using the microwave air-hydrodistillation method can improve the quality (aroma) of the obtained essential oils. Therefore it can be predicted that the patchouli oil obtained using microwave airhydrodistillation should have a better quality (aroma) than that obtained using the microwave hydrodistillation method.

\section{Analysis of electric consumption and environmental impact of patchouli oil extraction using the microwave hydrodistillation and microwave air-hydrodistillation methods}

In the extraction of patchouli oil using microwave hydrodistillation and microwave air-hydrodistillation, the extraction time is relatively fast, which is an advantage for both methods when compared to the extraction using conventional methods. 
Table 5 The composition of patchouli oil compounds obtained by microwave hydrodistillation (MHD) and microwave air-hydrodistillation (MAHD; air flow rate $5.0 \mathrm{~L} \mathrm{~min}^{-1}$ ). The microwave power was $600 \mathrm{~W}$ and the ratio of patchouli leaves to distilled water was $0.10 \mathrm{~g} \mathrm{~mL}-1 a$

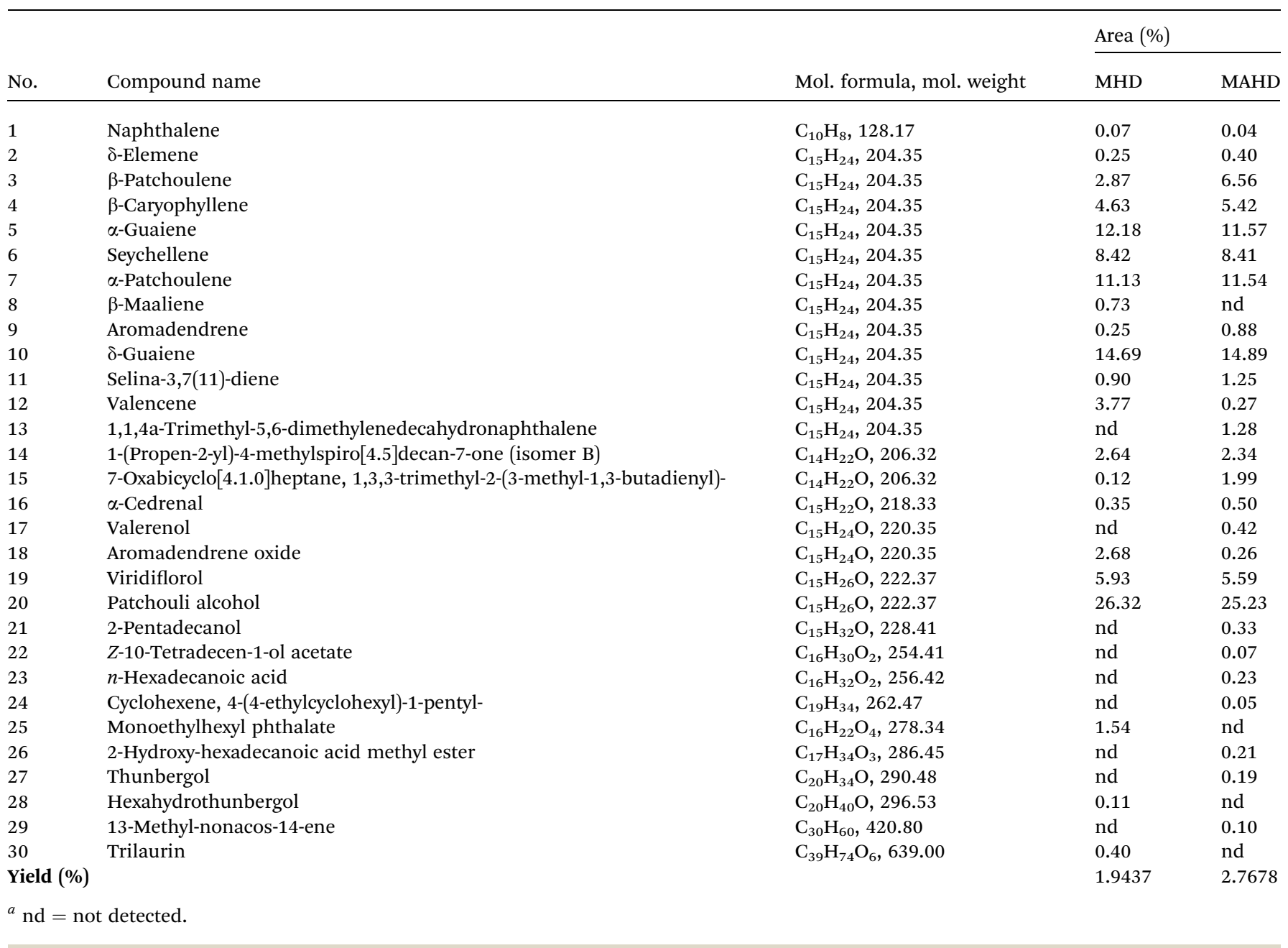

This is because the extraction time is related to the required cost and energy. To investigate this, we conducted an analysis of electric consumption and the environmental impact of patchouli oil extraction using the conventional method (hydrodistillation), the microwave hydrodistillation method and the microwave air-hydrodistillation method. Patchouli oil extraction with the conventional method (hydrodistillation) is done using a hot plate (Magnetic Stirrer SH-3) and an extraction time of 13 hours, while the extraction of patchouli oil using the microwave hydrodistillation and microwave airhydrodistillation methods is performed using a microwave and an extraction time of 2 hours. The difference in the extraction time causes the required cost and energy of patchouli oil extraction to be greater when using the conventional method (hydrodistillation) compared with the microwave hydrodistillation and microwave air-hydrodistillation methods. An analysis of electric consumption and environmental impact of patchouli oil extraction using the conventional method (hydrodistillation), and the microwave hydrodistillation and microwave air-hydrodistillation methods can be seen in Fig. 9.
In this study, the electric consumption requirements for patchouli oil extraction using the conventional method (hydrodistillation), the microwave hydrodistillation method and the microwave air-hydrodistillation method were 6.7000 , 1.2600 , and $1.5732 \mathrm{~kW} \mathrm{~h}$, respectively. Therefore it can be said that the patchouli oil extraction using the conventional method (hydrodistillation) consumes 5.3175 times more electricity than the microwave hydrodistillation method. In addition, the patchouli oil extraction using the conventional method (hydrodistillation) consumes 4.2589 times more electricity than the microwave air-hydrodistillation method, while patchouli oil extraction using microwave air-hydrodistillation consumes 1.2486 times more electricity than the microwave hydrodistillation method.

The required electricity to obtain $1 \mathrm{~g}$ patchouli oil from extraction using the conventional method (hydrodistillation), the microwave hydrodistillation method and the microwave airhydrodistillation method was equal to 6.5526, 1.6206, and $1.4210 \mathrm{~kW} \mathrm{~h}$, respectively. Therefore, it can be said that patchouli oil extraction using the conventional method (hydrodistillation) requires an electric consumption that is 4.0432 
times higher when compared with the microwave hydrodistillation method. In addition patchouli oil extraction using the conventional method (hydrodistillation) requires an electric consumption that is 4.6113 times higher when compared with the microwave air-hydrodistillation method, while patchouli oil extraction using the microwave hydrodistillation method requires an electric consumption that is 1.1405 times higher when compared with the microwave air-hydrodistillation method. Thus it can be assumed that patchouli oil extraction using the microwave air-hydrodistillation method requires lower operating costs when compared with the conventional method (hydrodistillation) or the microwave hydrodistillation method.

In general the environmental impact of the essential oil extraction can be seen from the produced $\mathrm{CO}_{2}$ emissions. If 1 $\mathrm{kW} h$ of energy from coal or fossil fuels is used, the amount of $\mathrm{CO}_{2}$ that is produced or released into the atmosphere is equal to $800 \mathrm{~g}$ during the combustion process. ${ }^{4}$ The $\mathrm{CO}_{2}$ emissions produced in patchouli oil extraction using the conventional method (hydrodistillation), the microwave hydrodistillation method and the microwave air-hydrodistillation method are equal to $5.3600,1.0080$ and $1.2586 \mathrm{~kg}$, respectively. Thus in general it can be said that the patchouli oil extraction using the conventional method (hydrodistillation) produces much higher $\mathrm{CO}_{2}$ emissions when compared with the microwave hydrodistillation and microwave air-hydrodistillation methods.

The $\mathrm{CO}_{2}$ emissions produced to obtain $1 \mathrm{~g}$ patchouli oil from extractions using the conventional method (hydrodistillation), the microwave hydrodistillation method and the microwave airhydrodistillation method are equal to 6.5526, 1.6206 and 1.4210 $\mathrm{kg}$, respectively. Therefore, it can be said that the patchouli oil extraction using the conventional method (hydrodistillation) produces $\mathrm{CO}_{2}$ emissions which are relatively much higher than those produced by the microwave hydrodistillation and microwave air-hydrodistillation methods. Therefore, the use of the microwave air-hydrodistillation method for patchouli oil extraction can be considered to be a new green technique.

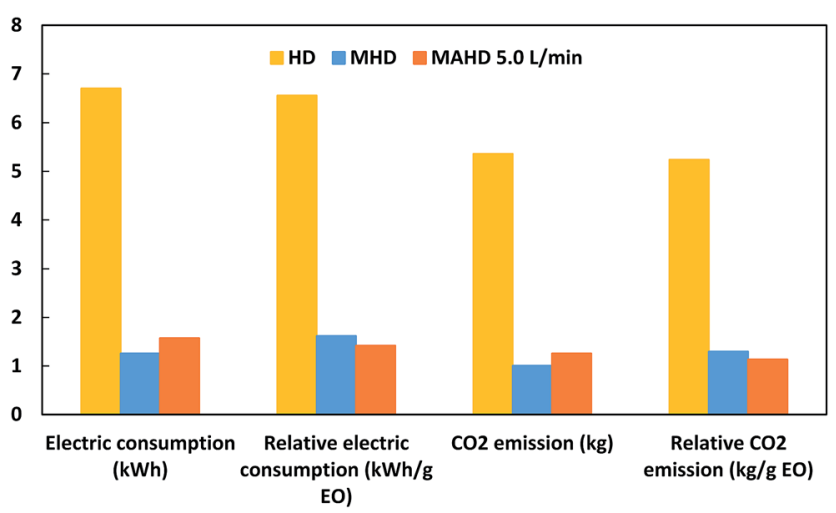

Fig. 9 The electric consumption and environmental impact $\left(\mathrm{CO}_{2}\right.$ emissions) for the extraction of patchouli oil by the conventional method (hydrodistillation; HD), the microwave hydrodistillation method (MHD) and the microwave air-hydrodistillation method (MAHD; air flow rate $5.0 \mathrm{~L} \mathrm{~min}^{-1}$ ). The microwave power was $600 \mathrm{~W}$ and the ratio of patchouli leaves to distilled water was $0.10 \mathrm{~g} \mathrm{~mL}^{-1}$.

\section{Conclusions}

Patchouli oil extraction using the microwave airhydrodistillation method is faster and produces better yields as well as a higher accumulated recovery when compared to the extraction using the microwave hydrodistillation method. The greater the air flow rate, the better are the yield and the recovery accumulation of the obtained patchouli oil. Thus, based on the yield and accumulation of recovery, it can be said that the addition of the air flow in the microwave air-hydrodistillation method enables the extraction (recovery) of more patchouli oil from the material (patchouli leaves) when compared with the microwave hydrodistillation method.

In addition, based on the results of composition analysis of the patchouli oil compounds by GC-MS, it can be seen that 21 compounds can be detected in the patchouli oil extracted using the microwave hydrodistillation method. When the patchouli oil extraction was carried out using the microwave airhydrodistillation method, 26 compounds were detected. Thus it can be said that the addition of the air flow in the microwave air-hydrodistillation method can help in the extraction of the heavy fraction oil components that originated inside the cell membrane or the plant tissue and did not diffuse out easily. The results show that the heavy fraction component contained in the patchouli oil obtained by the microwave airhydrodistillation method contains more constituent oils when compared with that obtained using the microwave hydrodistillation method. In the patchouli oil obtained by the microwave hydrodistillation method, there were only three heavy fraction components (mol. weight $\geq 228.41$ ) while the patchouli oil obtained by the microwave air-hydrodistillation method contained seven heavy fraction components (mol. weight $\geq 228.41$ ).

When kinetic modeling was conducted, it was found that the second-order kinetic model was better able to represent the experimental results of patchouli oil extraction using the microwave hydrodistillation and microwave airhydrodistillation methods when compared with the first order kinetic model. Based on an analysis of the physical properties of the patchouli oil obtained using the microwave hydrodistillation and microwave air-hydrodistillation methods, it can be said that the values for the refractive indexes and densities of the obtained patchouli oils were in accordance with quality standard ISO 3757: 2002(E).

\section{Competing interests}

The authors declare no competing financial interests.

\section{Author contributions statement}

Heri Septya Kusuma wrote the main manuscript text and Mahfud Mahfud prepared all figures and tables. Both authors reviewed the manuscript. 


\section{References}

1 M. Ma'mun, Characteristics of some essential oils from family Zingiberaceae in trade (in Bahasa Indonesia), Plant Research Bulletin of Spices and Medicinal, 2006, 17(2), 91-98.

$2 \mathrm{~W}$. Gunawan, Quality and value of essential oils, implications on the development of essential oil derivatives (in Bahasa Indonesia), Paper presented at the National Seminar with the theme: Chemistry with vision SETS (Science, Environment, Technology, Society) contribution to the advancement of education and industry, organized by the Indonesia Chemical Association Central Java, Semarang, March 21, 2009.

3 S. Adam, A. B. Siti Hana, M. Y. Mashitah and S. N. Tajuddin, Molecular dynamic simulation of the patchouli oil extraction process, J. Chem. Eng. Data, 2014, 59, 183-188.

4 N. Hamidi, Extraction of essential oils from patchouli plant using advanced techniques of microwave-assisted hydrodistillation, ARPN J. Eng. Appl. Sci., 2016, 11(2), 796799.

5 N. Kongkathip, P. Sam-ang, B. Kongkathip, Y. Pankaew, M. Tanasombat and P. Udomkusonsri, Development of patchouli extraction with quality control and isolation of active compounds with antibacterial activity, Nat. Sci., 2009, 43, 519-525.

6 A. Yahya and R. M. Yunus, Influence of sample preparation and extraction time on chemical composition of steam distillation derived patchouli oil, Procedia Eng., 2013, 53, 1-6.

7 Plantus, Distillation process of patchouli (in Bahasa Indonesia), 2008, available from: https://anekaplanta.wordpress.com/2008/ 02/28/proses-penyulingan-nilam/ on 6 January 2015.

8 M. A. Ferhat, F. Chemat, B. Y. Meklati and J. Smadja, An improved microwave clevenger apparatus for distillation of essential oils from orange peel, J. Chromatogr. A, 2006, 1112, 121-126.

9 E. E. Stashenko, B. E. Jaramillo and J. R. Martinez, Comparison of different extraction methods for the analysis of volatile secondary metabolites of Lippia Alba (Mill.) N. E. Brown, Grown in Colombia, and evaluation of its in vitro antioxidant activity, J. Chromatogr. A, 2004, 1025, 93-103.

10 F. Chemat, N. Sahraoui, M. Abert-Vian, I. Bornard and C. Boutekdjiret, Improved microwave steam distillation apparatus for isolation of essential oils comparison with conventional steam distillation, J. Chromatogr. A, 2008, 1210, 229-233.

11 H. S. Kusuma and M. Mahfud, The extraction of essential oil from sandalwood (Santalum album) by microwave airhydrodistillation method, J. Mater. Environ. Sci., 2016, 7(5), 1597-1606.

12 S. Lagergren, About the theory of so-called adsorption of soluble substances, K. Sven. Vetenskapsakad. Handl., 1898, 24(4), 1-39.

13 Z. Reddad, C. Gerente, Y. Andres and P. Le Cloirec, Adsorption of several metal ions onto a low-cost biosorbent: Kinetic and equilibrium studies, Environ. Sci. Technol., 2002, 36, 2067-2073.

14 Y.-S. Ho, Citation review of Lagergren kinetic rate equation on adsorption reactions, Scientometrics, 2004, 59(1), 171177.

15 Y.-S. Ho, H.-O. Adamou, H. Fauduet and C. Porte, Kinetics and model building of leaching of water-soluble compounds of Tilia sapwood, Sep. Purif. Technol., 2005, 45, 169-173.

16 R. P. Adams, Identification of essential oil components by gas chromatography/mass spectroscopy, Allured Publishing, Carol Stream, IL, 1995.

17 S. Arctander, Perfume and flavor chemicals, Allured Publishing, Carol Stream, IL, 1994.

18 Y.-S. Ho and G. Mc Kay, The sorption of lead(II) ions on peat, Water Resour., 1999, 33(2), 578-584.

19 E. F. Covelo, M. L. Andrade and F. A. Vega, Heavy metal adsorption by humic umbrisols: selectivity sequences and competitive sorption kinetics, J. Colloid Interface Sci., 2004, 280(1), 1-8.

20 E. Guenther, Essential oil volume 1, Translator Ketaren S., Universitas of Indonesia Press, Jakarta, 1987.

21 T. J. Betts, Evaluation of a "Chirasil-Val" capillary for the Gas Chromatography of volatile oil constituents, including sesquiterpenes in Patchouli Oil, J. Chromatogr. A, 1994, 664, 123-126.

22 M. A. Ferhat, B. Y. Meklati and F. Chemat, Comparison of different isolation methods of essential oil from Citrus fruits: Cold pressing, hydrodistillation and microwave 'dry' distillation, Flavour Fragrance J., 2007, 22, 494-504. 